\title{
Utilization of White Teak Sawdust Waste (Gmelina Arborea Roxb.) as Biodegradable Plastic
}

\author{
Achmad Amiruddin', Muhammad Farid Samawi², Maming3 \\ ${ }^{1}$ Environmental Management Study Program of Graduate School, Hasanuddin University, Makassar 90245, Indonesia. \\ ${ }^{2}$ Department of Marine Sciences, Hasanuddin University, Makassar 90245, Indonesia. \\ ${ }^{3}$ Department of Chemistry, Hasanuddin University, Makassar 90245, Indonesia.
}

Correspondence Author: Achmad Amiruddin, Environmental Management Study Program of Graduate School, Hasanuddin University, Indonesia. Email: aachmad007@gmail.com

Received date: 22 January 2020, Accepted date: 13 March 2020, Online date: 29 March 2020

Copyright: (C) 2020 Achmad Amiruddin et al. This is an open-access article distributed under the terms of the Creative Commons Attribution License, which permits unrestricted use, distribution, and reproduction in any medium, provided the original author and source are credited.

\begin{abstract}
The accumulation of plastic waste made from synthetic polymers for environmental pollution is needed on the defenders of life that are around it, so that to overcome them, it is needed plastic that is easily biodegradable and does not need environmental pollution. Polymers that can be used are natural polymers needed from the agricultural sector such as teak. This study aims to synthesize biodegradable plastics released from natural polymers containing cellulose fibers contained in waste teak sawdust (Gmelina arborea Roxb.) and compare cellulose masses based on optimal white teak sawdust in making biodegradable plastics. The stages of this research are cellulose extraction, making biodegradable plastics and testing the characteristics of biodegradable plastics (mechanical tests and FTIR analysis). The results showed that cellulose mass based on optimal white teak sawdust in making biodegradable plastics was 0.8 grams using chitosan and sorbitol plasticizers. The optimal tensile strength test result is $5.0449 \mathrm{~N} / \mathrm{mm} 2$ with $14.81 \%$ elongation percent.
\end{abstract}

Keywords: plastic, biodegradable, white teak sawdust, cellulose

\section{INTRODUCTION}

Plastic production and environmental pollution that accompany it have proven that plastic has become a major environmental problem. The effects of plastic waste on the marine environment, humans, and the environment at the time of public concern, so the need to save the ecosystem and life in it. Regarding plastic material, which is very useful in everyday life, substitute chemicals used in production need to be considered to ensure environmental health and safety. Reducing the use of plastic increases the chances of a clean environment and a healthy community [1].

The lack of degradability, as well as air problems and growing soil pollution, have led to the development of plastics. The use of more plastics and limited capacity available for the disposal of plastics requires more exceptional handling than plastic waste management [2]. Processing plastic waste in landfills, they use water and make high-quality chemicals. At present, most plastic is put in incinerators. Burning plastic in an incinerator will produce a variety of pollutants that are transferred to the air and soil which are significant sources of strong pollutants, including dioxins and other chlorinated organic compounds that are popular with their toxic effects on human health and the environment [3].

Awareness of the problem of plastic waste and its impact on the environment has increased interest in the field of polymers that can be degraded. Interest in environmental issues is growing and there is an increase in developing materials that do not burden the Environment significantly. Biodegradable plastic is considered as a better alternative because it is able to be degraded naturally by microbial activity. Biodegradable plastics are environmentally friendly plastics; they have a variety of potential applications and are easily supported by the use of plastic in packaging [4]. The development of most biodegradable plastics is assumed to reduce the use of fossil fuels and plastic waste and carbon dioxide emissions. These plastic biodegradability characteristics create a positive impact on society, and awareness of biodegradable packaging also attracts researchers and industry. Plastics can decompose naturally to produce air, carbon dioxide, and biomass, and cannot be used in the environment for years-produced [5].

The process of environmental chemical degradation is divided into two degradation environments, namely the biotic and abiotic environments. Degradation in the biotic environment generally occurs due to microbial attacks such as bacteria, mold, algae and 
others, while the degradation process in the abiotic environment includes degradation due to UV light, heat, hydrolysis, oxidation and others [6]. This biodegradable plastic can come from corn, cellulose, fats, and vegetable oils or micro-biota [7] [8]. Cellulose can be the main choice as a raw material for making bioplastics because the source of cellulose can be obtained from waste so that it can be a solution to overcome environmental problems. Cellulose is a polymer that forms a linear chain and is changed by $\beta-1,4$ glycosidic bonds. The linear structure causes cellulose to change crystalline and not easily dissolve. Cellulose is not easily degraded chemically or mechanically. In nature, cellulose is associated with other polysaccharides such as hemicellulose or lignin, which make it the main plant cell wall [9]. One of the wastes that contain a lot of cellulose is teak sawdust waste. Teak wood has $42-52 \%$ cellulose content [10], so it has the potential to be used as a raw material for making biodegradable plastics. The purpose of this study was to synthesize biodegradable plastic film based on cellulose-based on white teak sawdust with variations in cellulose mass to obtain high mechanical strength.

\section{MATERIALS AND METHODS}

This research aims to synthesize biodegradable plastics from white teak sawdust waste. The material used in this research is white teak sawdust originating from Pinrang Regency, South Sulawesi, Indonesia. Chitosan, sorbitol, $\mathrm{NaOH} \mathrm{2 \% ,} \mathrm{NaOCl} 5 \%$, $\mathrm{CH}_{3} \mathrm{COOH} 1 \%$ and $\mathrm{HNO}_{3} 0.05 \mathrm{~N}$.

Cellulose extraction from white teak sawdust

Wood sawdust is cleaned of impurities and dried. After drying, sawdust weighed 50 grams and added $500 \mathrm{~mL}$ of distilled water, which was then stirred for 2 hours at $50{ }^{0} \mathrm{C}$. Then the mixture is filtered and dried. The resulting residue was added $500 \mathrm{~mL}$ $\mathrm{NaOH} 2 \%$ with stirring for 2 hours at $80{ }^{\circ} \mathrm{C}$. Then filtered and dried. Furthermore, the resulting residue was added with $0.05 \mathrm{~N}$ $\mathrm{HNO}_{3}$ at $50{ }^{0} \mathrm{C}$. The mixture is filtered off and the residue taken is oven dried for 1 hour at $50{ }^{0} \mathrm{C}$ [11]. Cellulose extract was tested using FTIR.

Making biodegradable plastics

Sawdust weighed $0.2,0.4,0.6,0.8$ and 1 gram and added to the chitosan solution (4 grams chitosan $+150 \mathrm{~mL} \mathrm{CH}_{3} \mathrm{COOH} 0.6$ M) on each beaker and stirred. Subsequently added a $10 \mathrm{~mL}$ sorbitol plasticizer. Then stir for 15 minutes at room temperature and heated at $80{ }^{\circ} \mathrm{C}$ for 7 minutes. The mixture was printed on a glass plate and dried in an oven at $60{ }^{\circ} \mathrm{C}$ for 1 hour [12]. The plastic film produced is then tested for its mechanical properties using a Universal Testing Machine (UTM).

\section{RESULT AND DISCUSSION}

\section{Cellulose extract of white teak sawdust}

Cellulose extraction was carried out in 2 processes, namely delignification and bleaching [11]. The delignification process aims to remove lignin contained in wood dust. The brownish color of the filtrate produced when adding $\mathrm{NaOH}$ indicates that the delignification process is taking place. The bleaching process aims to remove the remnants of lignin and whiten the pulp to produce a white pulp called cellulose fiber. Cellulose yield obtained from 50 grams of white teak powder is 22 grams. The resulting cellulose can be seen in Fig. 1 .

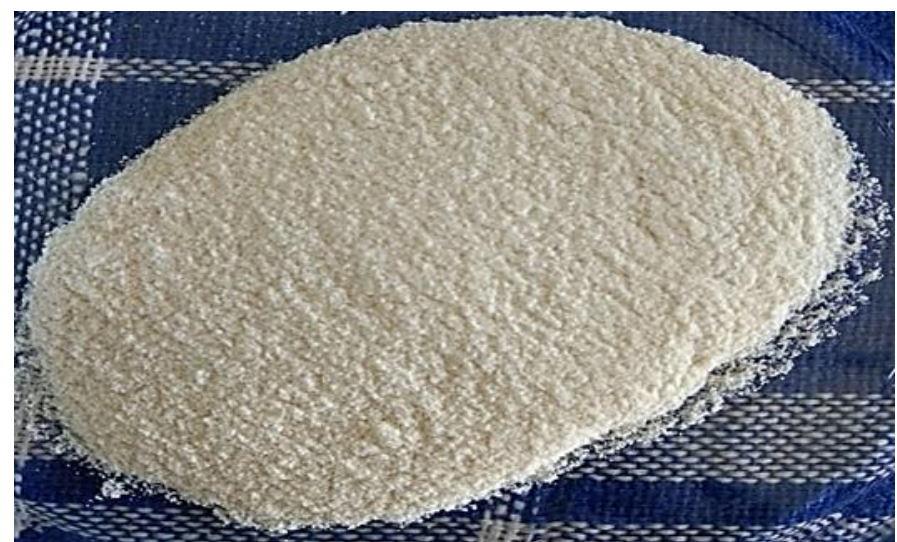

Fig. 1: Cellulose-based on white teak wood

\section{Characterization of white teak sawdust cellulose}

Wood cellulose extract was analyzed by using FTIR. The infrared spectrum of a fingerprint from a sample shows the absorption peak, which corresponds to the frequency of vibrations produced between the atomic bonds of the sample. Because each material is different from one another, which has each different set of atoms, no two compounds produce the same infrared spectrum. Therefore, infrared spectroscopy can be used for qualitative analysis of each different type of material. In addition, the size of the peak in the spectrum shows the amount of material available directly. 
The functional groups contained in cellulose are composed of glucose re-monomers, such as hydroxyl groups (-OH) and glycosidic C-O bonds. Based on Fig. 2, the resulting spectrum shows that the $\mathrm{O}-\mathrm{H}$ group is in the range of wavenumber of 3600 $\mathrm{cm}^{-1}$ to $3300 \mathrm{~cm}^{-1}$ and the absorption of $\mathrm{C}-\mathrm{O}$ in the range of $1300 \mathrm{~cm}^{-1}$ to $1000 \mathrm{~cm}^{-1}$.

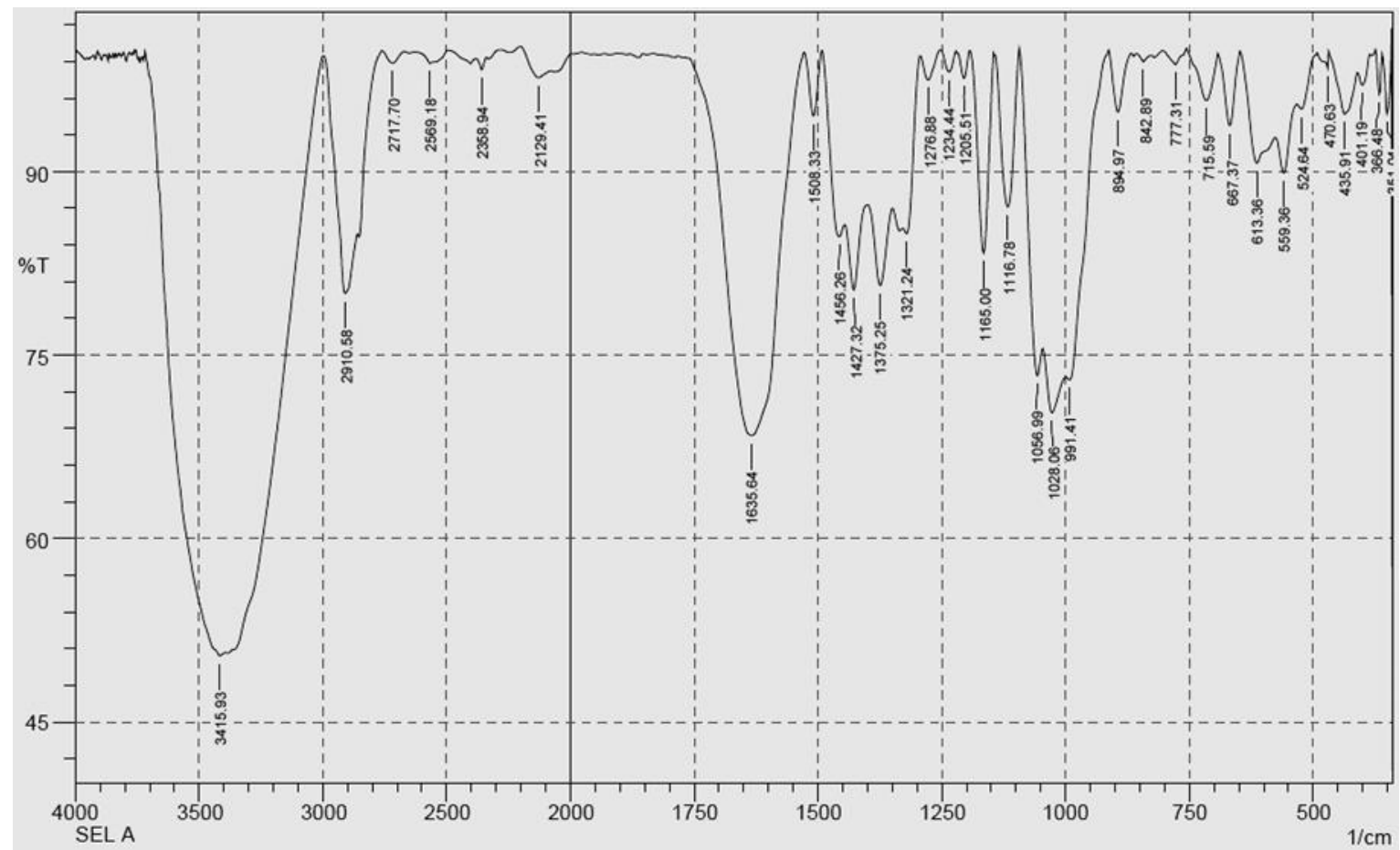

Fig. 2: Functional groups of cellulose extracts

Table 1: The FTIR absorption band of cellulose

\begin{tabular}{|c|c|}
\hline Functional Groups & Wave Number $\left(\mathbf{c m}^{-1}\right)$ \\
\hline O-H & 3415.93 \\
C-H & 2910.58 \\
C-O & 1028.06 \\
\hline
\end{tabular}

\section{Biodegradable plastic mechanical test}

Biodegradable plastic is made by reacting cellulose extracted with chitosan and sorbitol. The resulting biodegradable plastic film is a brownish yellow, flexible, and the surface is slightly smooth. The resulting plastic film can be seen in Fig. 3 . The mechanical property of biopolymers is one of the properties that is often used to characterize a polymeric material. Mechanical properties are a combination of high strength and good elasticity, and this property is caused by the presence of two kinds of bonds in biopolymer materials, namely strong bonds between atoms and interactions between weak polymer chains. The measurement of mechanical properties includes tensile strength and elongation. Tensile strength is the ability of a material to accept a load without being damaged or broken. Whereas elongation is the increase in the length of the test specimen, because of the withdrawal load until just before the test specimen is fractured.

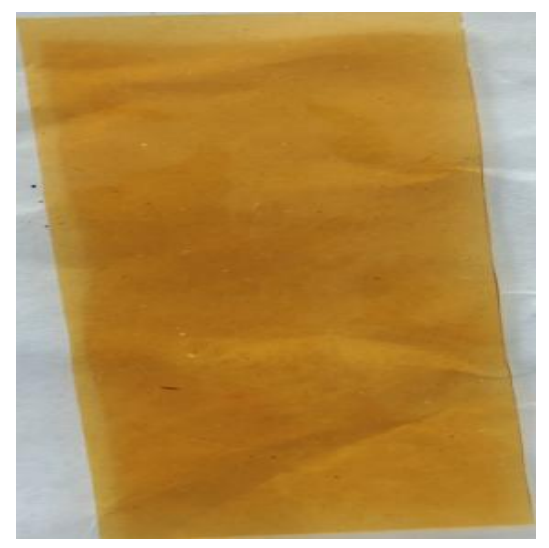

Fig. 3: Biodegradable plastic

The addition of sorbitol and chitosan in the manufacture of plastics aims to improve the mechanical characteristics of plastics. Cellulose variation is done to determine the optimum amount of cellulose that can be added in making plastics and determine the 
tensile strength and percent elongation of the bioplastic film itself, where cellulose molecules form long linear chains and have a tendency to form intra and intermolecular hydrogen bonds [12]. Hydrogen bonds can come from chitosan and sorbitol and significantly affect the tensile strength and percent elongation of bioplastic films.

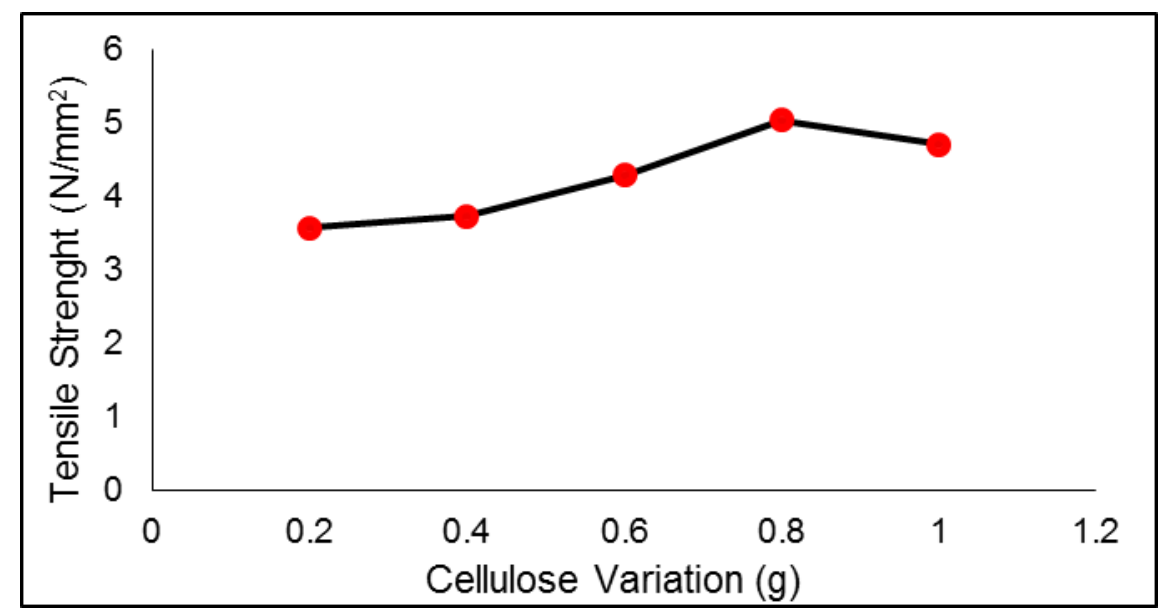

(a)

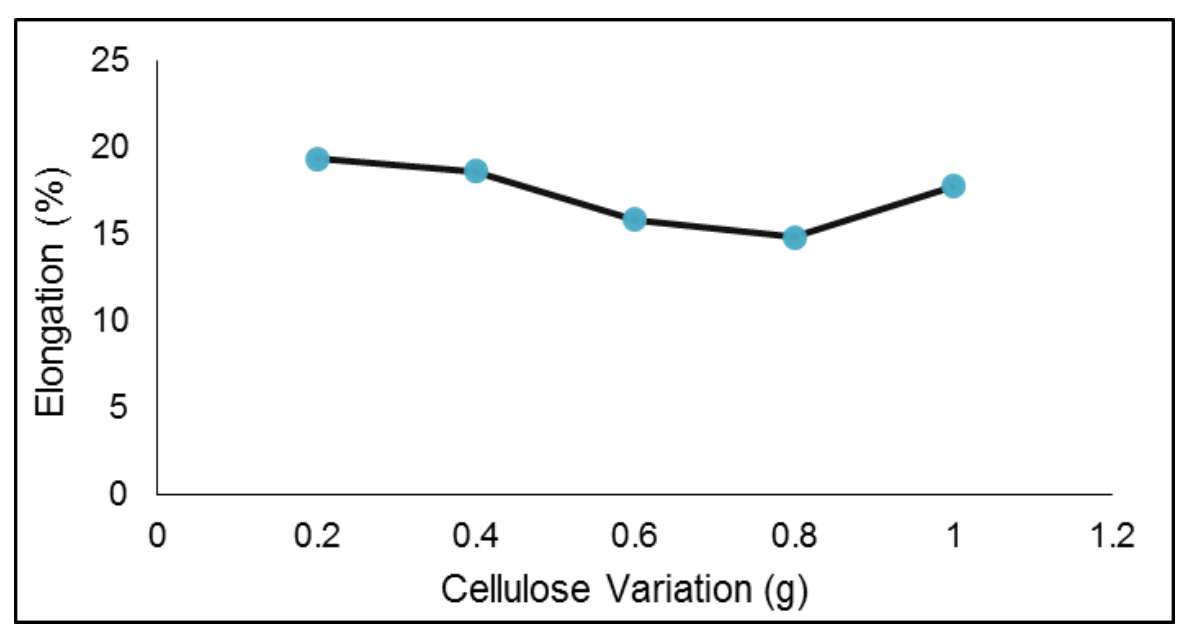

(b)

Fig. 4: Tensile strength (a) and elongation (b)

The graph of tensile strength and elongation value in Fig. 4 shows that cellulose with a mass of 0.8 gram has the highest tensile strength value of $5.0449 \mathrm{~N} / \mathrm{mm}^{2}$ with elongation percent of $14.81 \%$ and the lowest is cellulose with a mass of 0.2 gram with a tensile strength value of $3,5728 \mathrm{~N} / \mathrm{mm}^{2}$ and elongation percent $19.34 \%$. This shows that the optimum composition of cellulose addition is 0.8 grams. The addition of chitosan can increase the value of plastic biodegradable tensile strength [13]. High tensile strength is caused by the interaction between chitosan and cellulose polymers in the form of hydrogen bonds. Tensile strength decreases in 1 gram chitosan mass variation, which is $4.7081 \mathrm{~N} / \mathrm{mm}^{2}$ because the increase in cellulose mass is not proportional to the amount of chitosan, so it is not followed by the formation of interactions with plastic polymer chains [14]. The percentage rate of breaking extension is inversely proportional to the tensile strength of biodegradable plastics. The decrease in elongation is caused by a decrease in the number of hydrogen bonds formed due to suboptimal matrix binding of white teak wood cellulose fillers that causes pores in bioplastics to form, so the viscoelasticity response decreases, where the response causes biodegradable plastic to be stiffer, harder and less elastic. 


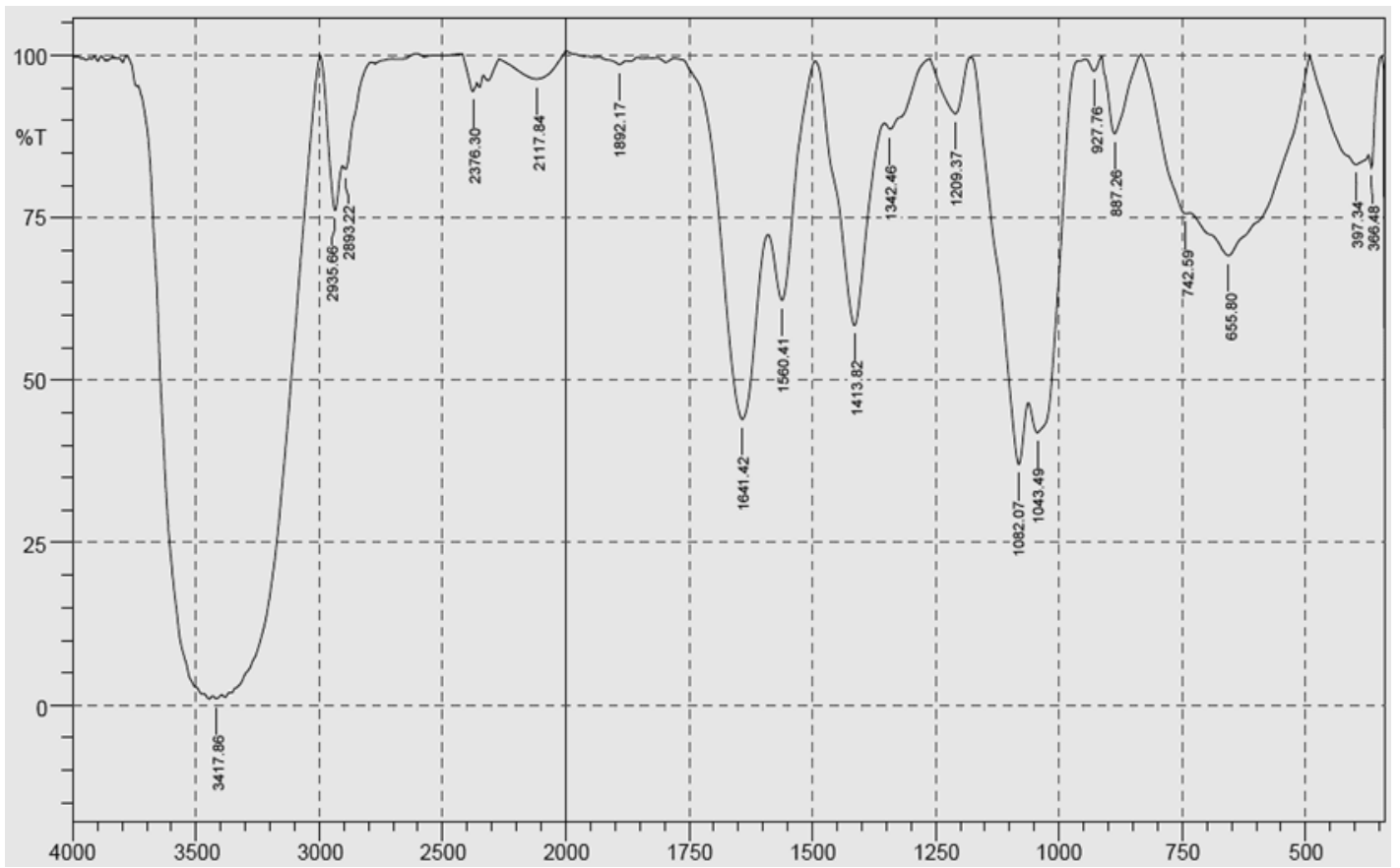

Fig. 5: Functional groups biodegradable plastic

Table 2: The FTIR absorption band of biodegradable plastic

\begin{tabular}{|c|c|}
\hline Functional Groups & Wave Number $\left(\mathbf{c m}^{-1}\right)$ \\
\hline O-H & 3417.85 \\
C-H & 2935.66 \\
C-O & 1209.37 \\
N-H & 1641.42 \\
\hline
\end{tabular}

Based on the analysis of the functional groups using FTIR spectrophotometer in (Fig 5). It can be seen that there are different absorption, which is located on the wavenumber at $3417 \mathrm{~cm}^{-1}$, which indicates the presence of the -OH group. The wavenumber at $2935 \mathrm{~cm}^{-1}$ indicates the existence of vibration $-\mathrm{CH}_{2}$ which is the building framework the cellulose structure is amplified by vibrations at wave number $2893 \mathrm{~cm}^{-1}$, the $\mathrm{CO}$ group arranging $-\mathrm{CH}_{2}$ at wave number $1209 \mathrm{~cm}^{-1}$ whereas at wavelength $1641 \mathrm{~cm}$ ${ }^{1}$ indicates the presence of $\mathrm{NH}_{2}$ functional groups of chitosan compounds. In addition, there is a C-O-C group at the peak of 1082 $\mathrm{cm}^{-1}$ that shows glycosidic bonds in cellulose. Based on the identification results, no new functional groups were found. This shows that the biodegradable plastic produced is a product of the results of the physical mixing method, wherein each mixing no new functional groups are formed.

\section{CONCLUSION}

Cellulose-based on white teak sawdust (Gmelina arborea Roxb.) it can be used as biodegradable plastic. The optimum mass of cellulose in making biodegradable plastics with the addition of chitosan and sorbitol plasticizers is $0.8 \mathrm{~g}$, with a tensile strength value of $5.0449 \mathrm{~N} / \mathrm{mm}^{2}$ with elongation percent $14.81 \%$.

\section{ACKNOWLEDGEMENT}

Authors thanks to Syahriani, Khairil Afdal, Tri Mei Yolanni, Muh. Askar, Asriani Hayatun for outstanding support in field and laboratory works, and also to staff of Chemistry Laboratory of Makassar State of University.

\section{REFERENCES}

[1] Alabi, O.A., Ologbonjaye, K.I., Awosolu, O. and Alalade, O.E, 2019. Public and environmental health effects of plastic wastes disposal: a review. Journal of Toxicology and Risk Assessment, 5 (1):1-13.

[2] Tiwari, A.K., Manisha, G. and Hardesh, K.M, 2018. Recent development of biodegradation techniques of polymer. International Journal Of Research - GRANTHAALAYAH, 6 (6):414-452.

[3] Pavani, T. and Rajeswari, T.R., 2014. Impact of plastics on environmental pollution. Journal of Chemical and Pharmaceutical Sciences, (3):87-93.

[4] Vignesh, R., Deepika, R.C., Manigandan, P. and Janani, R., 2016. Screening of plastic degrading microbes from various dumped soil samples. International Research Journal of Engineering and Technology, 3 (4):2493-2498. 
[5] Krepsztul, W.J., Rydzkowski, T., Borowski, G., Szczypiński, M., Tomasz, K. and Vijay, K.T., 2018. Recent progress in biodegradable polymers and nanocomposites based packaging materials for sustainable environment. International Journal of Polymer Analysis and Characterization, 23 (4):383-395.

[6] Mandal, S., Durgesh and Tumane P., 2017. Optimization and characterization of bioplastic produce by bacillus cereus. International Journal of Recent Scientific Research, 8 (4):16565-16571.

[7] Mukhopadhyay R, Sree K.D., Saneeha, R., Kale, P. and Iram, U., 2017. Preparation and characterization of biodegradable plastics out of food wastes as prospective and eco-friendly medical devices. International Journal for Research in Applied Science \& Engineering Technology, 5 (12):134-142.

[8] Chen, Y.J., 2014. Bioplastics and their role in achieving global sustainability. Journal of Chemical and Pharmaceutical Research, 6: 226-231.

[9] Oliveira, F.B.B., Julien, Pimenta, Maria, T.B., Curvelo, Antonio, A.S., Belgacem and Naceur, M., 2016. Production of cellulose nanocrystals from sugarcane bagasse fibers and pith. industrial crops and products, 93: 48-57.

[10]Lukmandaru, G. 2010., Chemical properties of teak wood (tectona grandis) at different growth rates. Journal of Tropical Wood Science and Technology, 8:188-96.

[11] Chandrahasa, R., Rajamane, N.P. and Jeyalakshmi, 2014. Development of cellulose nanofibres from coconut husk. International Journal of Emerging Technology and Advanced Engineering, 4 (4):88-93.

[12] Chadijah, S., Rustiah, W.O. and Munir, 2018. Determination of the optimum concentration cellulose baggase in making film bioplastic. IOP Conf.Ser: Journal of Phys. 979

[13] Olivera, J.P., Bruni, G.P., Lima, K., Halal S.L.M.E., Rosa, G.S., Dias, A.R.G. and da Rosa, Z.E., 2016. Cellulose fibres extracted from rice husk and oat husks and their application in hydrogel. Journal Food Chem. 221:153-60

[14] Hasan, M., Rahmayani, R.F. and Munandar, 2017. Bioplastic from Chitosan and Yellow Pumpkin Starch with Castor Oil as Plasticizer. Conf.Ser. Material Science and Engineering. IOP Publishing. 333:1-7. 